\title{
Criticizing the Economic Analysis of Law
}

\author{
Markets, Morals, and the Law. By Jules L. Coleman.* Cambridge: \\ Cambridge University' Press, 1988. Pp. xvii, 393. $\$ 16.95$.
}

\section{Jeremy Waldron $\uparrow$}

It is tempting to think that the influence of economics in jurisprudence is confined to those who style themselves adherents of "The Economic Analysis of Law" (EAL). But the methods of economic analysis have had an influence in legal studies that is in fact much wider than that. Partly this is because those who write in contemporary political philosophy find it necessary to be economically much more literate (and numerate) than they used to be. Opening a recent book on justice, democracy or moral obligation, one is as likely to be confronted by an indifference curve, a game theory matrix, or an Edgeworth box as by a piece of ordinary language analysis. Since jurisprudence is a part of political philosophy, it is bound to be affected by the way philosophers have opened the boundaries of their discipline to these other influences.

Partly, it is because economics is seen today as comprising much more than the narrow attempt to model general equilibrium or the decisionmaking of firms and households. To understand those topics, economists postulate a type of human agent who seeks rationally to maximize the satisfaction of his own wants in a context where others are engaged in a similar enterprise, against a finite stock of resources. That simple image of agent-as-maximizer proved remarkably fertile as economists were able to model interactions among very large numbers of people using the most modest assumptions, and to generate abstract results that were in fact quite powerful and interesting when applied to the messier reality of commerce, consumption and production in modern capitalist societies. Given that success, it was natural to try to extend these models of human choice and interaction into other fields and to apply them to other problems such as conflict-resolution, voting, adjudication, the formation of public policy, legislation, constitution-building, and so on.

The results of extending what has become known, at a general level, as the rational choice approach have not always been felicitous: Sometimes

\footnotetext{
* Professor of Law, Yale Law School.

† Professor of Law, Jurisprudence and Sacial Policy Program, Boalt Hall, University of California at Berkeley.
} 
we obscure more than we illuminate by cramming the terms of a problem into the narrow framework of individual utility-maximization. But the model allows us to say some of what we want to say much more precisely and pellucidly than we were able to before, and often this is the case even where we are convinced that there are aspects of a problem that rational choice cannot capture. So, for example, it is impossible to understand much of the modern discussion of the moral obligation to obey the law if one cannot distinguish between a prisoner's dilemma and a co-ordination game. The game theoretic framework may not capture the sense of patriotic duty that motivates many citizens in their support for the law, but it clarifies for us the role that such a motivation may play by exposing the limits and paradoxes in the interplay of more prudential or self-interested motivations.

In comparison with this general influence of economic or rational choice methods, EAL is a rather narrow phenomenon. It seeks to characterize certain areas of law in terms of the pursuit of efficiency. Rights are to be assigned in a way that promotes the efficient use of resources. In some cases this assignment will be the natural result of parties' dealings with one another: If a right is not already assigned to the person who can use it most productively, he should be in a position to purchase it from someone making a less productive use and still be in a position to derive advantage from the purchase. However, in cases where such dealings are impeded by transaction costs, it is the task of a court to determine how the rights would have been transferred apart from those costs and to assign them accordingly. So understood, EAL raises but does not settle a number of important questions. Why is the promotion of efficiency to be taken as the aim of the legal process? Why not justice or the maximization of utility or some other value that requires us to go beyond efficiency (however that is understood)? What reason is there to suppose (even within a rational choice framework) that judges will pursue this value and this value only? Crudely, what's in it for them? Moreover, what reason is there to suppose that this is what all people will want their courts to do? Is the promotion of efficiency also the task of legislation as well as judicial decisionmaking? Since the idea of efficiency presupposes a distribution of resources (and since it is evidently the task of law to endorse such a distribution as well as the transactions that flow from it), how are the values of distributive justice to be related to the pursuit of efficiency? Many of these questions can be addressed in terms of rational choice (broadly conceived). But few of them are addressed in the writings we associate with EAL.

Jules Coleman is not an adherent (or certainly he is a far from wholehearted adherent) of EAL. A number of the papers collected in Markets, Morals and the Law ${ }^{1}$ contain trenchant criticisms of that approach. But

1. J. Coleman, Markets, Morais, and the Law (1988) [hereinafter referred to by page 
his work as a whole bears tribute to the fertility of the economic method in legal and political philosophy. He knows the concepts and the techniques of rational choice theory, he is familiar with the important philosophical problems in law and politics, and he is more sensitive than most writers to dangers of sloppy or negligent use of the former to obscure rather than illuminate the latter. For example, we all know that "efficiency" is both a crucial and an ambiguous term in economic analysis-ambiguous, that is, between several perfectly well-defined meanings (such as Pareto-optimality, Kaldor-Hicks efficiency, and the maximization of interpersonally measurable utility). Much of the time, its use as a central concept in EAL plays on that ambiguity, making the approach seem stronger and more interesting than in fact it is. Coleman knows the ambiguities inside out, and he can spot an equivocation miles away. If readers get nothing else from his book, they will come away with these definitions ringing clearly in their heads, and their thought will be imbued with the lesson that the concept of efficiency that is actually used in the economic analysis must be the same as the one that is used to advertise its attractions. $^{2}$

Markets, Morals and the Law is a wide-ranging collection of papers, covering topics as diverse as Ronald Dworkin's critique of legal positivism, the difference between an auction and a competitive market, strict liability in torts, and the theory of voting in liberal democracies. All of the papers were previously published between 1976 and 1987 in law reviews and moral philosophy journals. Two of them, "Rethinking the Theory of Legal Rights" and "Morality and the Theory of Rational Choice," were co-authored with Jody Kraus, and one, "Justice in Settlements," with Charles Silver. That does not detract from the thematic unity of the collection, though it has to be said that the co-authored essays have been imperfectly edited for their inclusion here, slipping disconcertingly as they do from first person singular to first person plural in their presentation of arguments.

The thirteen papers are grouped into four sections: "Law and Morality," "Law and Economics," "Torts, Crimes and Settlements" and "Markets, Morals and Politics." I cannot hope to do justice to them all in one review, and I shall concentrate my critical comments on one paper from

only]. Throughout the book, Coleman takes the writings of Richard Posner as the main target of his criticisms of EAL, particularly R. POSNER, EConomic ANalysis of LAw (1986), Posner, A Theory of Nighgenre, 1 J. Legal Stud. 29 (1972), and Posner, Utilitarianism, Economics and Legal Theory, $8 \mathrm{~J}$. LEGAL STUD. 103 (1979). For reasons of space, I shall not in this review consider whether Judge Posner actually holds the views attributed to him by Coleman. My interest is in the force of Coleman's arguments themselves.

2. One possible disadvantage of collecting a set of previously published essays into one book is that the same concepts get introduced and re-introduced to the reader over and over again, each time as though they were new. Coleman defines and distinguishes the notions of Pareto-superiority, Paretooptimality, and Kaldor-Hicks efficiency near the beginning of each of the six chapters that discuss them. 
each section. That focus is not meant to suggest that the other essays are not worth reading. Also, my criticisms will pay tribute more to the reviewer's task of engaging the author than to any overall evaluation of the merits of the collection. Suffice to say that anyone who wants to talk intelligently about the application of economics and the theory of rational choice to law and jurisprudence ought to read these papers carefully.

I have chosen the targets of my discussion so that they hang together in two parts. Sections I and II examine a couple of problems in Coleman's discussion of tort law: (1) his critique of the EAL account of the role played by liability rules in the protection of entitlements, and (2) his discussion of corrective justice. In Sections III and IV, I focus on Coleman's discussion of some wider issues in economic theory: (3) his critique of various attempts to show that economic efficiency is a desirable goal for the law to pursue, and (4) his discussion of recent attempts to apply rational choice theory to the initial allocation of entitlements as well as to their subsequent exchange.

\section{Rights and Liability Rules}

How should we think about the liability to pay damages in tort? Suppose someone rams his car recklessly into mine, I sue him, and he pays me damages. Does that payment render his action retrospectively permissible? Does it make his ramming me legitimate in exactly the sense in which it would have been legitimated ex ante by, for example, my agreement to participate in a "Demolition Derby?" Should ex ante agreement and the payment of damages ex post be regarded as alternative ways of legitimately transferring entitlements?

In a chapter entitled "Rethinking the Theory of Legal Rights," Coleman and Kraus argue that the answer to these questions is often "No." It is clear that, in terms of the famous Calabresi-Melamed framework, ${ }^{3}$ the rights protected in tort characteristically involve elements of both "property rules" (invasions may be legitimated $e x$ ante by consent) and "liability rules" (compensation must be paid for unwanted invasions). But the combination of these elements need not be seen as involving alternative modes of legitimation. Coleman and Kraus believe that for many torts, the combination may take the following form:

(3') If the content of B's entitlement is given by a combination of property and liability rules, then B has two legitimate claims: One is

3. Calabresi \& Melamed, Property Rules, Liabnlity Rules and Inalienability: One Vieu of the Cathedral, 85 HARv. L. REv. 1089 (1972). A right is protected by a property rule if the right-holder may, with the support of society, enjoin any infringement that takes place without his consent; a right is protected by an inalienability rule if it is legally impossible for even an apparently willing rightholder to sell or give away his entitlement; and a right is protected with a liability rule if a person other than the right-holder may invade or reduce the value of an entitlement provided he compensates the right-holder afterwards. 
to ex ante agreement as both necessary and sufficient for legitimate transfer; the other is to recompense in the event A imposes a transfer on him after either negotiations fail or A forgoes them. ${ }^{4}$

The function of damages in this analysis is to bolster and reinforce the prohibition on unwanted (and therefore illegitimate) invasions. The rules in (3') protect a sphere of control or autonomy for B, by requiring $A$ to seek B's consent if he wants to invade B's entitlement. But they recognize that A may not always abide by the rules, and so they give $B$ the right to damages as something of a second line of defense. According to Coleman and Kraus, only something along the lines of (3') will be able to capture our sense that the reckless driver in the example given at the beginning of this section has done something wrong even if he was always willing to pay compensation. Indeed, as they note, since certain intentional torts warrant punitive damages and perhaps even criminal sanctions, no account will be adequate if it always allows the payment of compensation to legitimate an invasion ex post.

This is not to say that there are no cases where the payment of damages confers ex post legitimacy. A person may be permitted to engage nonnegligently in a dangerous activity like blasting provided he pays compensation to anyone who suffers damage thereby. ${ }^{\circ}$ Coleman and Kraus' point is simply that we cannot infer from the fact that the payment of damages sometimes legitimates an invasion to the claim that it is always understood to do so.

The latter claim, they believe, is suggested by much of what is said in the EAL approach to tort law. Adherents of EAL are driven to this position, which Coleman and Kraus describe as "ludicrous,"6 by the way in which they think about compensation. The line of thought goes as follows.

Suppose full compensation is understood as a transfer from the invader to the right-bearer which is sufficiently large to leave the latter at the same level of utility as he was just before the invasion took place, and suppose that the invader would rather invade the right and pay that level of compensation than not invade the right at all. Then it is natural to think of the whole transaction (invasion plus compensation) as a Paretoimprovement: It leaves the right-bearer as well off as he was before (the function of compensation), and it leaves the invader better off even having paid the compensation (otherwise he would not have invaded the right knowing that compensation would be due). It is natural to say that a transaction which is a Pareto-improvement cannot possibly be illegitimate: Who can possibly object, if both parties are at least as well off as they were before?

4. P. 42 (emphasis in original).

5. P. 50; see Spano v. Perini Corp., 25 N.Y.2d 11, 250 N.E.2d 31, 302 N.Y.S.2d 527 (1969).

6. P. 50 . 
Coleman and Kraus' response is to insist that many rights are intended to protect individual autonomy or individual control over resources, and not just a certain level of individual well-being. The illegitimacy of some such transactions (for example, in the reckless driver case) is simply that my entitlement was invaded without my consent, irrespective of my level of well-being. The proponent of EAL may respond that the acceptance of compensation amounts retrospectively to consent, but Coleman and Kraus insist that this makes nonsense of a perfectly coherent thought about the matter, namely, that an injured party may demand and accept damages $a s$ a recompense for having been wronged rather than as a way of establishing that he was not, in the end, wronged at all. ${ }^{7}$

I believe they are right about this, but they do underestimate the power of the EAL line in two ways. First, they do not take enough notice of the definitional connection between "adequate compensation" and "consent" that EAL insists on. There is no way in economics to establish that the right-bearer's utility has remained at the same level (after the invasion plus the payment of compensation) except to say that this is the least he would have accepted to consent to the invasion. That is what adequate compensation means, in the EAL approach. The other point is that Coleman and Kraus leave it a little unclear how the level of compensation is to be fixed, if it is not intended as a surrogate for consent. If it is understood simply as a sanction, why not fix it at whatever level is necessary to deter the invader rather than at the level necessary to secure the ex ante utility of the right-bearer? ${ }^{8}$

In all of this, Coleman and Kraus are developing a general theory of what it is to have a legal right. Since they want to argue that the liability to pay damages may or may not be a way of legitimating an unwanted transfer, they need to establish a conception of legal rights which does not identify rights analytically with either the application of property rules or the securing of a certain level of well-being through the application of liability rules. Classical liberals have sometimes argued that rights, by definition, can never be legitimately infringed without consent. ${ }^{9}$ Adherents of EAL have often responded by insisting that rights are nothing but ways of securing levels of utility, so payment of compensation is all there is to respecting a right. Coleman and Kraus seek to chart a middle course, in which the concept of rights begs as few questions as possible about the transaction structure that a particular right may involve.

I believe their general theory of rights is a useful one. It has a lot in common with what is known as the "Interest Theory" of rights developed in moral and political philosophy by Joseph Raz, Neil MacCormick, and

\footnotetext{
7. P. 52.

8. Coleman's answer to this question raises issues about corrective justice, which I discuss infra Section II.

9. E.g., R. Nozick, ANarchy, State, and Utopia ix (1974).
} 
others,${ }^{10}$ and the one criticism of it that I want to make relates to its divergence from the Interest Theory. To conclude this section, I briefly outline Coleman and Kraus' theory and my criticism of it.

In traditional positivist jurisprudence, a legal right is strictly correlative to a legal duty, and talk of legal rights is simply a way of talking about legal duties from the point of view of those who stand to benefit from their fulfillment. Rights and the duties imposed by legal rules are two sides of the same coin. The "Interest Theory" of Raz and MacCormick developed as a critique of that simple picture. MacCormick drew attention to cases in which it seemed possible to say determinately that a given person had a certain right without it being possible to say who had the correlative duty. ${ }^{11}$ And Raz insisted that we were often able to say confidently that a given individual had a certain right without being confident that we could specify a complete list of the duties that were owed to him in that respect. ${ }^{12}$ It was better, he argued, to conceive of rights as the grounds of duties rather than identify them as the duties themselves described, as it were, in the passive voice.

On Raz's approach, rights are identified with the normative significance of certain individual interests: To say that $\mathrm{X}$ has a right is to say that "an aspect of X's well-being (his interest) is a sufficient reason for holding some other person(s) to be under a duty."13 What the duty is, who bears it, and how many duties may be generated on this basis, are all left open by the identification of a given interest as the basis of a right. Moreover, not all interests give rise to rights on this account: Some interests are important enough to provide reasons for imposing duties while others are not. ${ }^{14}$ To say that $\mathrm{X}$ has a right to something is simply to identify an interest that is sufficiently important in itself to be capable of generating duties in this way. The virtue of this theory as an analytic framework is that it leaves open, as substantive normative questions, how the crucial interests are to be identified, whether they are invariably interests in liberty, what the duties are like, whether they are duties of restraint or assistance, whether they can be waived, and so on. Different substantive theories can give different answers to these questions while still sharing the analytic framework of the "Interest Theory" of rights.

Coleman and Kraus' approach is remarkably similar. They notice that the duties and facilities imposed by legal rules come in all shapes, sizes

10. Sit J. Raz, The Morality of Freedom 165-92 (1986); J. Waldron, The Right to Private Property 62-105 (1988); MacCormick, Rights in Legislation, in Law, MoRalrTy, AND Society 189-209 (J. Hacker \& J. Raz eds. 1982); Raz, Legal Rights, 4 OXford J. Legal STUd. 1 (1984).

11. MacCormick, supra note 10 , at 200-04.

12. J. RAz, supra note 10 , at $170-71$.

13. Id. at 166 .

14. In his critique of the "Interest Theory," Samuel Stoljar fails to see this. See S. STolJAR, AN ANALYSIS OF RIGHTS 31-35 (1984). 
and combinations, and that, on the whole, there is no point in identifying rights with any particular type of rule or duty or any particular transaction structure. Instead, they argue, the primary task in setting up a system of legal rights is to designate or mark out certain interests as worthy of protection: "rights are best understood as 'conceptual markers' or 'place holders,' used to designate a subset of legitimate interests or liberties to be accorded special protection by law."15 What that protection amounts to and, in particular, what it involves in the way of empowerment to transact exchanges or transfers, are likely to differ from right to right, making it impossible to infer simply from the concept of a right that, for example, a property rule must be involved.

So far, so good. The advantage of this approach is that it tries to settle as few issues as possible at the level of conceptual analysis, leaving all or most important controversies to be sorted out by substantive argument within the modest analytic framework that is laid out. But Coleman and Kraus also add a further element to his analysis which, I think, leads them into difficulties.

Once an interest has been given the privileged status of a right, we can ask (according to Coleman and Kraus) two questions about the legal rules that surround it. We can ask first what the privileged status of the interest consists in: Is the interest protected by a property rule, an inalienability rule, a liability rule, or some combination of these? And once we have answered that, we can ask how that protection is itself upheld and enforced: What remedies are available when the interest is invaded? How are breaches of the first set of rules deterred? The first is a question about the content of the particular right; the second is a question about its enforcement.

It may seem that Coleman and Kraus need this distinction because of what they want to say about the cases (such as our reckless driving example) where liability in tort operates as a sanction, rather than as part of the transaction structure. But even there they are ambiguous. Sometimes they say that the transaction structure (and thus the content of the right) is given by a combination of a property and a liability rule, along the lines of ( $\left.3^{\prime}\right)$ above. ${ }^{16}$ Elsewhere they say that the liability rule in ( $\left.3^{\prime}\right)$ is not part of the content of the right, but is to be understood rather as "a layer of potential 'enforcement' for entitlements whose conditions of transfer are otherwise fully specified by a property rule."17

I cannot see why the distinction is important. So long as it is understood that consent in these cases is necessary for legitimate transfer, what does it matter whether the liability to pay damages in the event of unwanted 
transfer is part of the right's content or part of the enforcement mechanism?

Moreover, what are we to say about the cases where an interest is protected only by a liability rule? Are we to say that the liability rule is necessarily the content of the right in that case (for lack of any other candidate), or can we continue to say that it is simply a layer of enforcement? Again, Coleman and Kraus' account leaves me with no idea how to answer this question (and no idea why it is important).

For reasons that are unclear, they seem to believe it is possible for interests to be protected by liability rules without attaining the status of rights. Not every claim to damages arises from the infringement of a right, they say. ${ }^{18}$ (They provide no example, but presumably have in mind cases in which purely economic losses may be compensable in tort if they have been caused through fraud or deceit.) But it is quite unclear what is lacking in these cases, given Coleman and Kraus' commodious conception of rights. An interest is marked out for legal protection, and the particular form that protection takes happens to be a liability rule associated with wrongful invasions of the interest. It is not very robust protection, and it does not cover invasions of all sorts, but the attraction of Coleman and Kraus' theory purports to be that the analysis of rights would beg no questions about the particular form of the protection. Maybe it is customary, on some more restrictive conception, to say that rights are not involved in these cases, because (for example) the interests are not protected by property rules. But the beginning of the essay creates the impression that Coleman and Kraus' intention includes challenging that restrictive approach.

\section{Torts and Corrective Justice}

Why should people be compensated for some of the losses they suffer? And why should that compensation be paid by the people who caused the loss? As we have seen, Coleman rejects the explanation that in all cases the payment of compensation is a way of legitimating ex post the imposition of the loss. He rejects the EAL story, in which liability rules promote efficiency in the face of transaction costs, at least as an account of many torts. But that leaves him with the task of providing an alternative account of why damages are due an injured party, at least in those cases where EAL is inadequate. In the chapter entitled "Corrective Justice and Wrongful Gain," Goleman examines the extent to which an Aristotelianstyle principle of corrective justice can take up the slack here.

It is part of Coleman's general approach to jurisprudence that most areas of law cannot adequately be understood in terms of the application

18. P. 46 . 
of a single overarching principle. Certainly, he thinks the principle of economic efficiency explains much less than adherents of EAL believe it does. But he believes that many of the traditional alternatives to the principle of efficiency, such as the principle of corrective justice, provide only partial explanations as well.

If it turns out, as I think it does, that only certain well-defined areas of tort law can be comprehended by a single principle, so much the better for my view, for it demonstrates theoretically what we know pretheoretically - namely, that the law of torts is extremely complex and that it resists simple analysis. ${ }^{19}$

I am sure this is true: Everything we know about the way the law develops argues for its eclecticism. But it would be interesting to see Coleman develop an account of that complexity in the general context of legal philosophy. Ronald Dworkin has argued that interpreting the law involves imposing a certain unity on a mass of materials that belies the diversity of its origins. ${ }^{20}$ Since Coleman's approach suggests that there are limits on our ability to do this, it would be interesting to see his response to Dworkin's arguments. Unfortunately, we do not have that yet, at least not in this volume. ${ }^{21}$

In the present chapter, Coleman argues that a principle of corrective justice can at most explain why, in the case of some torts, a plaintiff has a right to compensation. It cannot explain that in the case of all torts, such as strict liability for ultrahazardous activities or defective products. ${ }^{22}$ And even in the cases it covers (such as liability in negligence), it cannot explain why the person who caused the loss should be the one to pay the compensation that is due to the victim.

Unfortunately, Coleman nowhere provides any sustained discussion of corrective justice: What it is and what it involves. One difficulty with this collection is that Coleman has had to pick and choose which of his many publications should be included, and one or two which are, so to speak, crucial to the issues under discussion have been omitted. ${ }^{23}$ That makes the volume less useful as a general articulation of his views, more interesting as a tantalizing "sampler" of what Coleman has to say.

In the usual account of corrective justice, we are to imagine an existing distribution of goods or well-being that is regarded as just. An invasion of one person's interests, the interests of $\mathrm{A}$, by the actions of another person,

19. P. 189.

20. R. DWOrkin, Law's EMpIre 176-225 (1986).

21. There is a discussion of Dworkin's earlier arguments in the chapter entitled "Negative and Positive Positivism," which I have no space to examine here, but the book contains no discussion at all of Law's Empire.

22. P. 189.

23. For example, Coleman, On the Moral Argument for the Fault System, 71 J. PHIL. 473 (1974); Coleman, Justice and the Argument for No-Fault, 3 Soc. Theory \& Prac. 161 (1974). 
B, disrupts that order. Now A has less than he had under the just distribution, and perhaps $B$ has more. The solution seems to involve tampering with the resulting holdings of both A and B: B's holding should be reduced by the amount of his wrongful gain and A's increased by the amount of his wrongful loss. "The principle of corrective justice requires the annulments of both wrongful gains and losses."24

There are several things to notice about this principle. First, it presupposes some independent criterion for determining just and unjust distributions of resources. One criticism that is sometimes made is that corrective justice provides no explanation at all for a tortfeasor's duty to compensate his victim, if the latter already had more goods than he would have been entitled to under an ideal distributive order. The answer may be that the law endorses the existing (pre-tort) distribution as just, even if we (as theorists of justice) do not, and that is all that is necessary to explain why the law requires compensation as a way of restoring that distribution. If we disagree with the initial endorsement, of course we will disagree that restoring it counts as corrective justice; but that does not mean that corrective justice fails to capture the claim that the law is making. Still there is something to the objection. Many people think of torts as wrongs that require redress whether they think the initial distribution was just or not. ("Never mind about just distributions. We can't have people going round recklessly imposing losses on one another.") A theory of corrective justice simply cannot capture the sense that the issues are independent in this way.

A second point is one to which Coleman devotes most of his chapter. A theory of corrective justice can explain why A's losses should be repaired and B's gains annulled, but it cannot explain why B should be the one to pay the compensation to $A$. There is no reason whatsoever to suppose that B's wrongful gains are equal to A's wrongful losses. For one thing, it may be hard to pin down any particular gain that a tortfeasor has secured. Coleman notes quite rightly that a person who drives negligently secures whatever gain he does (for example, by not shouldering the burden of taking care) whether he injures anyone or not. He gains nothing extra if he injures someone, but it is only in that case that he has to pay anything: There is no wrongful gain specifically correlative to the defendant's wrongful loss. "The wrongful gain negligent motorists secure is logically distinct from any loss they may cause others, and so the occasion of another's loss cannot be the moral basis for annulling these gains as a matter of justice." ${ }^{25}$

24. P. 185. The prototype of such accounts is Aristotle's discussion of rectificatory justice in 5 Aristotle, Nichomachean Ethics, 1131b-32b (D. Ross trans. 1954).

25. P. 187. As Coleman notes, the appropriate way to annul the wrongful gain that accrues to ntgligent drivers is to impose a fine for careless driving. "In this way we can treat this category of wrongful gains similarly by not imposing any additional burden on those particular faulty injurers [ I 
Coleman's conclusion is that in these cases the theory of corrective justice plays only a limited role. It explains A's right to compensation, but it does not explain who should bear the duty to compensate. ${ }^{26}$ If we impose the duty on the tortfeasor B, it must be for independent reasons, such as deterrence, administrative convenience, or retribution for wrongdoing. But Coleman is on shaky ground here. Take retribution first. The same logic that associates wrongful gain with all careless driving (whether it causes loss to anyone or not) will also associate moral guilt with all careless driving, and so fail to explain any rule that imposes the particularly severe penalty of having to compensate $A$ on the particular driver who injured him. Indeed, if the aim of retribution is to penalize people in proportion to the wrongness of their conduct, there is no reason to suppose this bears any relation to the amount of their victim's loss. A moment's carelessness may cripple a person for life, while a malicious intention may, as it turns out, occasion only a slight injury. Retribution explains why tortfeasors should be penalized, but it does not explain (what we assume in tort) that the victim's loss is the best guide to the appropriate scale of the penalty.

The other justifications run into even deeper trouble. Suppose that B has secured only a slight wrongful gain from injuring $A$, but that we decide for reasons of social policy (deterrence or accident cost avoidance) to impose the full duty to repair A's loss on B. Then B must suffer a loss; that is, $B$ ends up with substantially less than he was entitled to under the just distribution before the incident took place. Apart from his slight wrongful gain, he is in as bad a position (relative to the just distribution) after the payment of compensation as A was before the payment. So if A's position cried out for repair on grounds of corrective justice why is the same not true now of B's?

The response, I imagine, would be that B's loss was not "wrongful" in the appropriate sense. But that will not do. The imposition of this loss on $B$ is not justified by his wrongful gain, and it may not be justified by any principle of retribution. It is as wrongful as any other disruption of an individual's entitlement under a just order for the sake of social convenience. Since social convenience is seldom the principle underlying just distributions, it is unlikely to justify what would otherwise be a wrongful derogation from such a distribution.

Part of the problem is that Coleman gets tangled up in the notion of wrongfulness and in the idea that it is only in the case of wrongful losses that corrective justice demands repair. I agree that there will be some dis-

take it Coleman means 'drivers'] who, though they do not gain further by their mischief, are unfortunate enough to cause another harm." Pp. 198-99.

26. On some accounts of rights-those tied tightly into a correlativity conception-that is incoherent. For $\mathrm{X}$ to have a right is simply for there to be an identifiable $\mathrm{Y}$ who has some duty towards him. But Coleman has adopted a more spacious conception of rights than that and, as I have already explained in Section I, this part of his account is preferable to the correlativity model. 
tinction, in a theory of corrective justice, between losses that demand repair and those that do not. But for the purposes of such a theory (particularly as Coleman wants to deploy it), that distinction simply cannot be one of wrongdoing or moral fault on the part of the person who causes the loss. There is nothing in the idea of corrective justice that can possibly link up with retributive considerations in this way. Particularly if one takes Coleman's line that whether there is a repairable loss can be determined quite independently of who has the duty to repair, then the idea that repairable losses are all and only those that result from culpable conduct seems quite unfounded.

There is a more sensible distinction between repairable and nonrepairable losses. Any sophisticated theory of distribution envisages the possibility of individuals' holdings changing over time. Some people will consume more of their chocolates than others, and they will come to have less as a result. Some will invest part of their holding in a fair lottery, and some of these investors will lose (while others will win). To enjoy such gains and suffer such losses is the very reason that resources are distributed to people. It is part of an assignment of a holding to someone, and the determination of how much should be assigned already takes this into account. But not all distributive vicissitudes will be regarded in this way. Some of the losses that people suffer (or some risks of loss) are not part and parcel of what it is normally to enjoy a holding. These are the ones that we regard as actually disrupting the distributive order (rather than consummating it, so to speak). Different theories of justice will draw this distinction in different ways, ${ }^{27}$ but most will put suffering a loss as a result of someone else's negligence into this category, along with suffering a loss as a result of confiscation imposed for the sake of the greater good.

One advantage of this approach, by the way, is that it explains a class of cases that Goleman cannot. If I break into your mountain cabin to escape a blizzard, my action is probably not wrongful since it is justified through necessity. But you are still owed compensation for the damage to your cabin. The explanation is simply that you have suffered a loss relative to your just entitlement. Having windows broken by necessitous strangers is not a normal incident of enjoying a holding; in this respect it is unlike the wear and tear on the property occasioned by one's own use. Corrective justice calls for restoration of the status quo after I break into your cabin even though nobody has done anything wrong. Something similar may be said about the compensability of losses in cases of strict liability. (Of course, nothing here settles the issue of who should pay the compensation in these cases, but Coleman does not think that that is settled by corrective justice in any case.)

27. For a particularly clear example, see Dworkin, What is Equality?-II. Equality of Resources, 10 Phil. \& PuB. AfF. 283, 292-345 (1981) (distinction between brute luck and option luck). 
From all of this, it seems that Coleman's eclectic approach to tort law will not work. A tort system involves compensation for certain losses, and it involves imposition of the duty to compensate on those who cause the losses. Coleman thinks that corrective justice can explain the first but not the second of these elements, but he says that there is "nothing in my view that is incompatible with establishing a tort system to annul wrongful losses." ${ }^{28}$ That is a mistake. If Coleman's theory of corrective justice explains why plaintiffs have a right to compensation, it also explains why defendants should not be forced to bear the loss of paying that compensation. If it does not explain the latter, it cannot explain the former.

\section{The Economic Analysis of LaW}

According to the proponents of EAL, the touchstone of legal decisionmaking should be the promotion of efficiency in society. Of course this is only one of the claims made by EAL. It is normative in character whereas some EAL claims are descriptive as well, arguing that the promotion of efficiency as a goal is the best way of characterizing legal decision-making, and perhaps even the best way of predicting it. But it is the normative claim I want to attend to.

In one of the most influential essays in this collection, "Efficiency, Utility and Wealth Maximization," Coleman develops a critique of this claim. He notes, first of all, that "efficiency" is often insufficiently defined, with EAL theorists shifting among Pareto-superiority, Pareto-optimality, Kaldor-Hicks superiority, and the maximization of wealth. His own precision in the definition of these concepts is, as I remarked at the beginning of this review, one of the most attractive features of these essays. Only when we have a clear idea of what these standards involve can we say anything useful about their justification. Those who defend these efficiency standards usually do so on one or both of two grounds: individual liberty or social utility. Coleman has critical things to say about both lines of defense.

The defense in terms of liberty seems clearest in cases where the promotion of efficiency is understood in terms of the facilitation of Paretoimprovements. It seems desirable to facilitate Pareto-improvements because the transactions that yield such improvements are characteristically transactions that people will engage in voluntarily if they are left free to deal with one another on their own terms. The argument appears persuasive, but in fact it faces a number of difficulties.

A first objection, according to Coleman, is that if we tie liberty and Pareto-improvement together this tightly, we rule out by definition the possibility of a person's acting freely to his own detriment. ${ }^{29}$ But in fact

28. P. 200.

29. Pp. 123-24. 
this point shows only that the Paretian standard does not provide an argument for transactional freedom. It does not in itself undermine the argument in the other direction, from transactional freedom to the desirability of pursuing Pareto-improvements, and that is the one that is important here.

The real difficulty with the libertarian defense shows up when we ask, "In what sort of case is the facilitation of Pareto-improvements going to be an issue?" There are two classes of cases to consider. If a Paretoimprovement has or is about to take place as a result of the free interaction of the parties concerned, then of course a principle of liberty provides a good reason for not disturbing or impeding it, although it also provides a good reason for not impeding a voluntary transaction which does not yield a Pareto-improvement. But these are not the cases that concern EAL.

The cases with which EAL is concerned are those where a Paretoimprovement is in principle available, but the parties have not secured the gain because of imperfections like limited information or high transaction costs. In these cases, according to EAL, the law should intervene to promote the Pareto-improvement because the parties are unable to secure it for themselves. Coleman points out, devastatingly, that whatever the justification for this sort of intervention, it cannot be based on liberty. ${ }^{30}$ Defenders of liberty are interested only in how free people actually are. We do not promote actual liberty in the real world by forcing through transfers that the parties might have entered into freely in an ideal world. To mimic coercively what a system of free transactions might have produced under ideal conditions is merely to mention freedom, not to promote it.

Utilitarian justifications for intervention in these cases seem no better. For one thing, the very idea of using utilitarianism to justify the pursuit of efficiency (in a Paretian sense) is odd, since the former is much more controversial than the latter. As Coleman points out, many philosophers doubt whether the utilitarian standard can justify anything. Since the pursuit of aggregate utility characteristically involves the imposition of net losses on certain parties, it seems itself much more in need of justification than the Pareto standards, which never involve such trade-offs.

Having said that, however, I want to show that Coleman's particular criticisms of the efficiency/utility connection are vitiated by a number of errors.

Consider first the notion of a Pareto-improvement: A move is made from one situation to another such that at least one person prefers the new situation to the old one and no person prefers the old situation to the new. Is such an improvement desirable from the point of view of classical utilitarianism? ${ }^{31}$ The answer seems obvious: Since a Pareto-improvement in-

31. For simplicity, I shall concentrate on a version of utilitarianism which seeks to maximize the 
volves nothing but the enhancement of someone's preference-satisfaction, it must amount to an increase in total utility.

Coleman argues that this answer is acceptable only if there exists a standard for comparing the utilities of different individuals:

If the Pareto-superior standard is to be an index of total utility, interpersonal utility comparisons are necessary, since the concept of total utility presupposes the capacity to aggregate individual utility functions, which in turn requires a standard of comparison. Provided such a standard exists, Pareto improvements increase total utility; and because they do, one could argue that the justification for pursuing Pareto improvements relies on its connection to utilitarianism. ${ }^{32}$

His argument seems to be that since the existence of a standard of interpersonal comparisons is a necessary condition for the meaningfulness of the concept of aggregate utility, any doubts about the existence of such a standard will undermine the claim that the pursuit of aggregate utility justifies the pursuit of Pareto-improvements. I think Coleman's argument is misleading, but the difficulty needs to be stated carefully.

The first thing to note is that the problem concerns cardinal utilities. ${ }^{33}$ Suppose we can establish that I value wine twice as much as I value beer, and that you value wine three times as much as you value beer: the problem, for a utilitarian, is to find a way of expressing the value that I attach to wine or beer in terms of the value you attach to either of these beverages. Unless he can do that, the utilitarian will be unable to say whether transferring a given bottle of wine from me to you raises or lowers aggregate utility.

Those who impugn the interpersonal comparison that this calculation requires may be raising either an ontological or an epistemic issue. The ontological issue is whether there really exists a basis for expressing the utilities of wine and beer for me in terms of the utilities of wine and beer for you. We can of course choose any one of an infinite number of comparability conventions, but the ontological difficulty concerns the existence of

total amount of utility rather than the average. (For arguments that show that the latter is in fact more attractive, see J. RAwls, A TheORY OF Justice 161-66 (1971).) Coleman misleadingly suggests that the choice between these alternatives involves matters of distribution. $P$. 96. That is false: Average utilitarianism involves no greater concern with distribution than total utilitarianism does. If "average" meant "median" or "mode," then some minimal information about distribution could be inferred from knowledge about average utility. But in the ethical literature, "average utility" is always understood as "mean utility"-that is, the total utility divided by the number of persons whose utility is in question.

32. Pp. 100-01.

33. It is possible to define a notion of aggregate ordinal utility which does not require interpersonal comparisons. But the usefulness of such a concept is limited, and it can do hardly any of the work that the traditional utilitarian principle is supposed to do. Utilitarians base their judgments on cardinal aggregate utility, which requires interpersonal comparisons. In what follows, "aggregate utility" should always be taken to mean "aggregate cardinal utility." I am grateful to Jody Kraus for bringing this point to my attention. 
a non-arbitrary basis for such a choice. An ontological skeptic may say there is no truth of the matter, in regard to the claim that wine affords you greater satisfaction than it affords me, or in regard to the claim that one person's pain or pleasure is more intense than another's.

Even if we are not persuaded by the ontological difficulty, there may still be a problem of knowledge and application. How can we be sure that we have chosen the right convention of comparability? And how is such a standard to be applied in practice?

Let us take the ontological difficulty first. Suppose there exists no basis in reality for comparing the utilities of two people. Does that mean that the phrase "aggregate utility" is meaningless? The answer is obviously "No." After all, we had to appeal to its meaning in order to discover that it presupposed the existence of a standard for interpersonal comparisons. A piece of gibberish would not even tell us that much. Now, the meaning of the phrase can tell us other things as well, things that are quite independent of what it tells us about the need for a standard of interpersonal comparisons. For example, the word "aggregate" has certain implications. The idea of aggregating or summing several quantities logically implies that if one of these quantities goes up while none of the others goes down, then the aggregate or sum must go up. This is true whether we are talking about utility, money or weight. Applied to utility, this reasoning establishes that if one person is made better off by a policy which makes no person worse off, then aggregate utility must increase. But this is exactly the connection between utilitarianism and Pareto-superiority that Coleman called in question. It is an implication of the idea of aggregate utility that is quite independent of the issue about interpersonal comparisons of utility. It follows from the logic of "aggregation" not from anything special about its aplication to utility.

Of course, if we find that there is no standard of interpersonal comparability, then establishing this connection between utility and Paretosuperiority will have been to no avail. But even in advance of knowing how the ontological issue will turn out, we can say this: If there is anything to the notion of aggregate utility at all, then a Pareto-improvement is always an increase in aggregate utility.

The point becomes even stronger if our difficulty with interpersonal comparisons is only epistemic. For then we can say categorically that a Pareto-improvement is always an increase in aggregate utility. Since Pareto-improvements can be identified whether we can reliably discern and measure differences in the utilities of different people or not, our epistemic doubts about interpersonal comparisons need not affect the link between the Pareto-judgments and utilitarian judgments. The epistemic difficulties will afflict only those cases in which claims are being made about changes in aggregate utility that do not involve Pareto-improvements. So whether our doubts about interpersonal comparisons are ontological or 
merely epistemic, they do not impugn the conceptual connection between Pareto-improvements and aggregate utility.

Utilitarians define right action in terms of aggregate utility. But it is important to remember that not just any increase in aggregate utility counts for them as the right thing to do. And here Coleman's criticism is nearer the mark. Although any Pareto-improvement involves an increase in aggregate utility, not every increase in aggregate utility is a Paretoimprovement. Sometimes utility overall may be increased by a policy which actually frustrates the preferences of some people. If interpersonal comparisons are available to make sense of that, they may also enable us to say that a given Pareto-improvement increases utility by less than a policy which is not a Pareto-improvement. Circumstances can be imagined in which the latter policy is an opportunity cost of the former: We have a choice between making a Pareto-improvement and increasing utility by more through a policy which involves losers. In such a case, utilitarians would recommend the latter choice, and condemn the Pareto-improvement as wrong. Of course, if we are unable to make interpersonal comparisons, we will not be in a position to know which non-Pareto-improving policies are superior to a given Pareto-improvement. But lack of such knowledge does not amount to utilitarian endorsement of the Pareto-improvement faute de mieux. What it means is that the utilitarian, by his own lights, is unable to say whether the Pareto-improvement is the best policy or not.

What about Pareto-optimality? How does that stand to aggregate utility? Many allocations of resources are Pareto-optimal in the sense that no Pareto-improvement is possible from them. Since there is no reason to believe that every Pareto-optimal allocation contains the same amount of aggregate utility, there is no basis whatever for identifying "Paretooptimal" with "greatest aggregate utility." Once again, of course, we may not be able to tell that one Pareto-optimal allocation contains more aggregate utility than another. What we can say is that, if (counterfactually) we could make interpersonal comparisons of utility, we would not expect all Pareto-optimal allocations to contain the same amount, and that is sufficient to refute the alleged connection between Pareto-optimally and utilitarianism. So far, so good.

Unfortunately, Coleman goes on to obscure this point in two ways. He says that we can make no judgments about the relative utility content of the various members of the set of Pareto-optimal distributions "because the set of Pareto-optimal distributions cannot be compared by the Paretosuperiority standard." ${ }^{34}$ The reason given is correct, but it is quite irrelevant. The Pareto-superiority of one state to another is a sufficient but not a necessary condition for the former having more aggregate utility than the latter. In principle, then, there can be distinctions of aggregate utility 
between allocations, whether some of those allocations are Pareto-superior to others or not. (But, as always, it may be impossible for us to make judgements about these distinctions.)

Goleman also says, misleadingly, that "whether Pareto optimality is rooted in utilitarianism will depend on whether Pareto-superiority is." Again that confuses a sufficient with a necessary condition. Paretosuperiority's being "rooted in utilitarianism" can only mean that a Pareto-improvement is a sufficient condition for a utilitarian improvement. Suppose that relation holds. Still, nothing follows about Paretooptimality. There may be utilitarian improvements from a Pareto-optimal position, despite the fact that there can be no Pareto-improvements. And the move to a Pareto-optimal position may increase aggregate utility, whether the move involves a Pareto-improvement or not. The only thing we can say about the relation between Pareto-optimality and aggregate utility is that, for any given Pareto-optimal state $S$ there are other states containing less utility-those states that are Pareto-inferior to it. This is a very weak relation indeed.

The notion of Kaldor-Hicks superiority (KH-superiority) is not identical to either of the Pareto-standards, and it is often thought to have a much stronger relation to the standard of aggregate utility than they do. One allocation is $\mathrm{KH}$-superior to another if those who gain in a move from the latter to the former gain enough so that they could compensate those who lose and still have some increase in utility left over. It looks as though $\mathrm{KH}$-superiority is necessary as well as sufficient for an increase in aggregate utility. If some persons' utility goes down while aggregate utility is increased, then some other persons' utility must have gone up. Moreover, it must have gone up by more than the amount the others' utility went down, or else there can have been no increase in the total. That point can be represented in terms of a sum of increments in utility: The winners must enjoy both an increment in utility which, if transferred to the losers, would exactly compensate them for their loss, as well as some additional increment in utility over and above this amount. That looks exactly like the $\mathrm{KH}$ standard. It is natural to think that $\mathrm{KH}$ superiority is a necessary and sufficient condition for a utilitarian improvement.

Coleman questions whether a $\mathrm{KH}$-improvement is sufficient for an increase in aggregate utility. He adduces something called the Scitovsky paradox, which shows that there may be two allocations, A1 and A2, each of which is $\mathrm{KH}$-superior to the other ${ }^{36}$ But $\mathrm{A} 1$ cannot contain more utility than $\mathrm{A} 2$ while $\mathrm{A} 2$ contains more utility than $\mathrm{A} 1$. So KH-superiority can-

35. P. 103.

36. The paradox is named for its discussion in an article by Scitovsky, $A$ Note on Welfare Propostions in Eronomics, 9 REv. OF ECON. STUD. 77, 88 (1941). 
not be a sufficient condition for a situation's containing more utility. Coleman makes a great deal of this point, emphasizing several times that it simply destroys the link between Kaldor-Hicks and the principle of utility. But it does not. He notes himself that the Scitovsky paradox can be avoided by defining a slightly stronger version of $\mathrm{KH}$ (which I call $\mathrm{KH}^{*}$ ): $\mathrm{A} 1$ is $\mathrm{KH}^{*}$-superior to $\mathrm{A} 2$ if $\mathrm{A} 1$ is $\mathrm{KH}$-superior to $\mathrm{A} 2$, and if $\mathrm{A} 2$ is not $\mathrm{KH}$-superior to A1. "This," says Coleman, "eliminates the paradox, but then Kaldor-Hicks will not be transitive." "37 This is quite misleading: $\mathrm{KH}$-superiority is not transitive, but $\mathrm{KH}^{*}$-superiority, as defined, is transitive. And $\mathrm{KH}^{*}$-superiority is both necessary and sufficient for an increase in aggregate utility.

Notice two general points about this relation between $\mathrm{KH}^{*}$-superiority and aggregate utility. First, as always, it presupposes interpersonal comparisons of utility. And second, it does not imply that in any situation a given $\mathrm{KH}^{*}$-improvement is, from a utilitarian point of view, the right thing to do. We have already seen that the concept of an increase in aggregate utility and the right thing to do for a utilitarian are not the same. The right thing to do will always be $a \mathrm{KH}$-improvement, but right action for the utilitarian involves selecting which increase in aggregate utility (and therefore which $\mathrm{KH}$-improvement) yields the greatest total.

That second point is important because it illustrates that nothing in all of this provides a utilitarian defense of either the Pareto or the $\mathrm{KH}^{*}$ standard. The link between Pareto superiority and an increase in utility does not amount to a utilitarian defense of the former because utilitarians are distinguished not by their demand for just any increase in utility but by their demand for the greatest increase in aggregate utility available. And the same is true for $\mathrm{KH}^{*}$. So even if utilitarianism is the best justificatory theory available (which, as Coleman notes, many doubt), and even if everything I have said is true, nothing has been shown to justify the use of either Pareto-superiority or $\mathrm{KH}^{*}$-superiority as the principle to be applied in the courtroom.

Notice also that, even if they were successful, neither of these defenses (the one based on liberty or the one based on utility) would show that the pursuit of efficiency should be the sole concern of the law. Very few people deny that efficiency (especially in a Pareto sense) is a good thing. What they deny is that this is the only criteria by which economic processes and outcomes are to be assessed. In particular, they insist that considerations of equality, distributive justice, desert, and need should play a part in the assignment of rights. What is unpalatable about EAL is not its concern with efficiency, but its obsession with it to the exclusion of everything else.

37. P. 104 (footnote omitted). 


\section{Pre-Market Contracts}

There cannot be a market unless there are property rights, and to the extent that economics studies markets, the discipline presupposes at least a set of initial entitlements of persons over things. People bring something to the marketplace looking to exchange it for what others bring. The idea that such exchanges are Pareto-improvements and the idea of market efficiency that is built on that assume that no one must trade unless she wants to. So what one brings to the market must be not merely holdings, but holdings over which one has rights.

It is often assumed that economics has nothing to say about the initial distribution of these rights. Initial distribution is a matter of power, or it is a matter of equity and justice, but it is not a subject on which economists have anything distinctive to say. Of course it is important. The distributive features of a market equilibrium (who ends up with what) are profoundly affected by the initial distribution (who begins with what). Since any number of resource allocations, both equal and unequal, can be efficient, efficiency as such-which economists do understand-confers no distributive legitimacy whatever on either the outcome or the starting point of market interaction. If there are objections to the starting point, there will be objections to the finishing point, and nothing about equilibrium or efficiency answers those objections. The point is not that an objectionable set of initial endowments calls in question the freedom or rationality of subsequent transactions (though that may also be true). It is simply a matter of legitimacy in, legitimacy out. ${ }^{38}$

Though economists, qua theorists of the market, have nothing to say about the determination of initial holdings, there is no reason to think that the more general theory of rational choice should be silent on the issue. Coleman is aware of this and devotes an interesting section of his essay "Market Contractarianism" to a discussion of the emergence of a set of property rights in terms of rational choice.

Historically, the pioneer of the rational choice approach to the emergence of property rights is David Hume, and its most distinguished recent

38. The point is most clearly stated in D. GaUthIER, Morals By AGReEment 94-95 (1986):

The operation of the market is to convert an initial situation specified in terms of individual factor endowments into a final outcome specified in terms of a distribution of goods or products among the same individuals. Since the market outcome is both in equilibrium and optimal, its operation is shown to be rational, and since it proceeds through the free activity of individuals, we claim that its rationality leaves no place for moral assessment. Given the initial situation of the market, its outcome cannot but be fully justified. But neither the operation of the market nor its outcome can show, or even tend to show, that its initial situation is also either rational or morally acceptable. . . Market outcomes are fair if, but of course only if, they result from fair initial condit: ns. 
exponent is the Nobel laureate James Buchanan. ${ }^{38}$ The particular version of that approach that Coleman discusses ${ }^{40}$ proceeds as follows.

Postulate a set of individuals in an environment where there are material resources they can use. The individuals will grab whatever resources they can, and these will be their holdings. There is nothing legitimate about these possessions; they amount simply to what the individuals can retain. Moreover, they will seize part of the holdings of others whenever they can and try to retain those, too. Indeed, each person will devote a considerable amount of time and energy to attacking the holdings of others and defending his own against others' depredations. In time, it will occur to these people that everyone might be better off by cooperating with others in the protection of holdings. For example, if there are economies of scale in the provision of protection, an individual contributing to a cooperative protection scheme might end up paying less than he would in protecting his holding himself. Suppose this is true of each individual, no matter what the size of his holding: Protection can be provided to him at a unit cost that is less than the cost to him of providing it himself. Then it is in the interest of each individual to cooperate in such a scheme. Setting up such a scheme involves establishing institutions of specialist enforcement (in effect, a state or a legal system), and it involves the recognition by those institutions of each person's holding as something to be protected. Since protection will be afforded by the central enforcement of rules prohibiting invasion or takings without consent, such a scheme amounts to a regime of property rights. The holdings that the individuals have a reason to protect in this way are now regarded as rightful, just in the sense that they are protected by the enforcement of such rules. With this scheme in place to prevent depredation, a market, involving now the strictly z'oluntary transfer of holdings, can get underway.

That, in brief, is the story Coleman wants to consider. It is not a story that he accepts; his technique as usual is to set it out, with considerable technical clarity, and then attack it, largely on technical grounds, showing that the claims that are made for it are more shaky than they might appear.

As it stands, the story certainly seems to have its difficulties. For one thing, there is likely to be a free-rider problem with regard to the provision of protection. If it is costly or difficult to exclude those who do not pay for the protection agency from the benefits of its operation, people might be tempted to enjoy its benefits without contributing to its costs. We cannot say simply that the protection agency can use its coercive power to exact contributions as taxes, for if the temptation to free-ride is wide-

39. D. Hume, a Treatise of Human Nature 484-567 (L.A. Selby-Bigge ed. 1888); J. Buchanan, The Limits of Liberty (1975). It is surprising to find no reference whatever to Hume in Coleman's discussion of this theory.

40. Pp. $262-65$. 
spread, it threatens the very possibility of constituting these coercive mechanisms in the first place. ${ }^{41} \mathrm{We}$ can call this Hobbes' problem: The prisoners' dilemma of the state of nature cannot be solved by the setting up of leviathan, since the setting up of leviathan itself involves the solution of what appears to be a similar collective action problem. ${ }^{42}$

That is one difficulty. Another, and the one to which Coleman devotes most attention, is the bargaining problem involved in the realization of the gains that accrue from setting up cooperative protection. Though everyone in possession of a holding stands to gain, how much each gains will be a matter of negotiation. Since the initial holdings are not given as equal, and since individuals are not equally capable of defending whatever holdings they have, their threat advantages (the utility to each of the cooperative scheme's foundering, that is, of his having to fall back on his own defensive resources) are not the same. Some parties may hold out for a better deal, and this holding-out has costs for all. Coleman argues that we cannot simply assume that because cooperative protection is more efficient in itself than individual protection, it therefore retains this edge of efficiency once the costs of bargaining behavior are taken into account. ${ }^{43}$

The general point that he stresses here is well-taken: Since every Pareto improvement involves a potential surplus, and since the improvement will not be made unless the parties can reach a bargain concerning the division of the surplus, and since bargaining is itself not cost-free, we cannot infer that every Pareto-improvement that is in principle available will be secured in fact.

This in turn yields a more general critique of welfare economics. Economists often argue that since efficiency and distribution are conceptually distinguishable, the institutional mechanisms for promoting efficiency can be, and ought to be, quite distinct from the institutional mechanisms concerned with the distribution and redistribution of wealth. But Coleman's emphasis on the bargaining problem indicates that there are often distributional questions to be settled in the course of our pursuit of efficiency.

\footnotetext{
41. P. 266.
}

42. In fact, as Jean Hampton has shown, the collective action problem involved in the constitution of a Hobbesian sovereign is not a prisoners' dilemma, and hence not identical to the problem its institution is supposed to solve. J. Hampton, Hobres and the Sccial Contract Tradion $132-88$ (1986).

43. P. 274. But Coleman neglects one special feature of the situation we are discussing. The cost to individuals of protecting their holdings, and the advantages that joint protection would offer, are, as it were, endemic. Holdings must be protected indefinitely, and it will always be the case, even if a particular bargain fails, that cooperative protection, minute by minute, is cheaper. That is, we are not dealing with a one-off situation, in which a potential gain from trade may evaporate if a bargain is not reached. It is a feature of David Hume's account of this process that the "convention . . . to bestow stability" on possessions "arises gradually, and acquires force by a slow progression." $D$. Hume, supra note 39, at 490 . (As we shall see, this is one of several respects in which Hume's version of the rational choice story is more sophisticated and more interesting than the version Coleman considers.) No matter how many times we fail to reach agreement through holdouts, there is still a gain to be realized from returning the next day to the bargaining table, since every day our holdings must be protected. 
In cases where prices are not set by a perfectly competitive market, the parties must bargain for the division of gains from trade or else they will not secure them.

One response to this may be to say that although bargaining for the division of gains from trade involves $a$ distributive issue, it does not involve the main issue of the distribution of wealth. The wealth that the parties bring to the bargaining table, and therefore the area on the Paretofrontier where their bargain may be struck, are determined independently of what they agree to in their bargaining. That may be true in some cases, although it seems unlikely that what the parties think about the division of the surplus will be utterly unrelated to what they think about distribution generally. ${ }^{44}$ It is in a relevant way untrue of the bargaining situation we are discussing at present. Since the bargain to be struck is precisely an agreement to recognize holdings of wealth, disagreements about the division of the surplus are always liable to spill over into disagreements about the distribution of the holdings to be recognized.

One effect of the bargaining problem is that even though everyone gains, the bargain is likely to leave some in a situation where they gain less than they might. As Coleman puts it, "whatever agreement is reached, those who feel they are exploited will seek to destabilize the agreement, and there is ample opportunity for them to do so."45 They will try constantly to force renegotiation to redistribute the cooperative surplus. We may interpret this possibility as simply part of the long-term bargaining process involved in the emergence over time of a single Humean convention. After all, the rational choice story is understood as a model of what happens, not a blow-by-blow account. ${ }^{46}$ But we should see also that there is no guarantee that a Humean convention will secure for all time the stability of the pattern of holdings it recognizes. If over time the operation of the convention changes the balance of power, then we expect that to result in a challenge to the terms of the convention. I shall return to this below.

As if this were not bad enough, Coleman argues that the agreement problem in the state of nature will be aggravated by certain features of the property rights scheme. The institution that is to provide the cooperative

44. This is complicated by the fact that there is still no consensus among rational choice theorists as to whether there is a unique solution to the bargaining game. See pp. 272-76; see also pp. 311-42 (reviewing argument on the issue in D. GaUTHIER, supra note 38 ).

45. P. 274.

46. As Coleman recognizes:

[E]ven if rational choice theory cannot provide an account of the actual emergence of political institutions, it might nevertheless provide an account of the contingent rationality of political association (that is, a theory about why the move from anarchy to polity is rational) and an account of the specific conditions or principles of rational political association (that is, a specification of the outcome of the rational bargain that takes place in order to overcome pre-market market failure).

P. 267. 
protection will necessarily be a monopoly. ${ }^{47}$ It is therefore in a position to collect an amount of revenue greater than that minimally needed to provide the necessary protection, generating a surplus shared effectively as rent among the providers. This aspect of monopoly taxation and rentseeking may seriously distort the payoffs associated with the original potential for Pareto-improvement, and it will certainly further distort the bargaining process. ${ }^{48}$

I am sure Coleman is right about all this, but it is worth noting how the argument depends on features of his version of the rational choice story which are quite different from the versions of Hume and Buchanan.

In Coleman's story, the potential for Pareto-improvement consists simply in economies of scale and specialization so far as the protection of holdings is concerned. What changes, when the system of property rights is set up, is that people no longer have to defend their holdings themselves. Coleman does not say that the agreement involves any mutual renunciation of depredation: He seems to suggest that the threat to holdings remains constant and that it is only the mode of defense that is altered.9

In contrast, the convention in David Hume's version of the story is nothing but a convention of mutual restraint:

I observe, that it will be for my interest to leave another in the possession of his goods, provided he will act in the same manner with regard to me. He is sensible of a like interest in the regulation of his conduct. When this common sense of interest is mutually express'd, and is known to both, it produces a suitable resolution and behaviour. . . . [S]ince the actions of each of us have a reference to those of the other, and are perform'd upon the supposition, that something is to be perform'd on the other part. ${ }^{50}$

Property rights, for Hume, do not arise out of the institution of protection or enforcement mechanisms. They arise out of "this convention, concerning abstinence from the possessions of others." ${ }^{21}$ The parties recognize that they gain more by not attacking one another's holdings, and by not having to defend their own against such attack, than they do from continuing to pursue the temptations and the risks of predation. (The same is true of Buchanan's version: The parties agree to accept the respective holdings that they have already secured and to refrain from attacking the

47. For discussion of the emergence of a monopoly protection agency and its transformation into a Weberian state (an organization that insists on having a monopoly over rights enforcement), see $\mathrm{R}$. Nozick, supra note 9, at 54-146.

48. Pp. 268-71.

49. This is a little unclear. His technical account of the arithmetic of the Pareto-improvement suggests that the savings in the shift from individual to cooperative protection include saving the costs to oneself of attacking others' holdings. Pp. 264-65.

50. D. HuME, supra note 39 , at 490 .

51. Id. 
holdings of others.) Although it does not set up a state or an institutionalized legal system, the Humean convention still generates rules and a sense of obligation. But those notions are understood primarily in terms of the "internal aspect" that grows out of a shared understanding of the agreement, rather than in terms of the external enforcement which characterizes Coleman's version of the story. ${ }^{52}$

This makes a difference to Coleman's characterization of the agreement problem. First, if the agreement is one of mutual restraint, it is not at all clear that there is serious bargaining to be done before the gains to the parties can be realized. If each party refrains from attacking the holdings of others, then each gains (more or less automatically) an amount equal to the previous cost to himself of attacking others' holdings plus the previous cost to himself of defending against others' attacks plus the rost of the losses he would incur if his defenses failed (times, of course, the probability of their failing). And each loses an amount equal to the amount by which he could augment his holding by attacking others' (discounted, this time, by the probability of their defenses failing). The Humean assumption is that the sum of these gains and losses is positive in the case of each person. But my present point is that these gains and losses accrue to the parties as a direct consequence of mutual restraint. Their accrual does not depend on bargaining. That $\mathrm{X}$ and $\mathrm{Y}$ agree to mutual restraint is all that is necessary for $\mathrm{X}$ to achieve this gain: His gain results directly from his not attacking $\mathrm{Y}$ and from his not being attacked by him.

Second, if the initial agreement, securing the Pareto-improvement, is simply mutual restraint, the questions of monopoly pricing and rentseeking do not arise (at least, not immediately). Since the agreement institutes only a shared normative order, the provision of the public good of mutual security does not require any specialized class or coalition of providers.

Coleman might respond by saying that the Humean convention is bound to be hopelessly fragile in the absence of an enforcement mechanism. People will always have a temptation to violate the rights that they have recognized. There are three points to make in response to this.

(1) Though the model indicates a single act of agreement, the Humean version assumes that in reality the agreement will stabilize over a long period of time:

Nor is the rule concerning the stability of possession the less deriv'd from human conventions, that it arises gradually, and acquires force by a slow progression, and by our repeated experience of the inconveniences of transgressing it. ${ }^{53}$

52. For the internal aspect of rules, see H. Hart, The Concept of Law (1961).

53. D. Hume, supra note 39 , at 490 . 
Hume, like Hobbes, assumes that the prisoners' dilemma of cooperation in the state of nature is iterated and that cooperative strategies may be rational in the long-term even though violation is immediately tempting. ${ }^{54}$

(2) James Buchanan associates this dynamic aspect of the situation with another. A Pareto-improvement is to be expected from a Humean agreement only as the parties discover the limits of their respective predatory capacities. Since time immemorial people will have been seizing, using and fighting over resources:

In any case, as a result of the actual or potential conflict over the relative proportions of [resources] to be finally consumed, some "natural distribution" will come to be established. This cannot properly be classified as a structure of rights, since no formal agreement is made, although there might well exist mutual recognition of the appropriate bounds on individual action. Nonetheless, the natural distribution may represent a conceptual equilibrium, in which each person extends his own behavior in securing (defending) shares in [resources] to the limit where marginal benefits from further effort are equal to the marginal costs that such effort requires. ${ }^{55}$

Such a distribution might be equal or unequal, but the parties will already know that they cannot hope for a much better distribution by pitching their own strength yet again against that of others.

(3) Hume acknowledges that there is a role for a government in providing each with an assurance that others will take a long-term view of the advantages of iterated cooperation and not succumb to "their violent propension to prefer contiguous to remote" advantages. ${ }^{56}$ People will agree to set up and obey a government that will enforce the terms of the original agreement, and thus "acquire a security against each others weakness and passion, as well as against their own." But the point is that the institution of a coercive power is understood quite independently of the agreement on the bounds of property. Coleman's claims about the monopoly character of such a power remain valid, of course; but they are now theoretically distinguishable from whatever bargaining problem is involved in the agreement to recognize property.

It is time to take stock. The rational-choice story, whether in Coleman's version or in Hume's, imagines the institution of a system of property rights based on and recognizing the holdings that people happen to have acquired through processes (such as occupancy and depredation) that are quite independent of agreement. Suppose the difficulties Coleman identifies can be overcome. What does this show?

54. T. Hobbes, Leviathan 201-06 (C.B. Macpherson ed. 1982).

55. J. Buchanan, supra note 39 , at 24 .

56. D. Hume, supra note 39 , at 537 .

57. Id. at 538 . 
It shows that a complete account of the institution and operation of a market economy can be given in rational choice terms. Apart from the story we have been considering, economists had simply to assume a set of individuals endowed with initial entitlements; their account of markets was predicated on that assumption. Now we have an account of the existence of such entitlements, an account that uses the same terms (the terms of rational choice theory) that are used in characterizing the market itself. It is therefore important for the completeness of rational choice theory in this area that the story be closely scrutinized, and that is the merit of Coleman's discussion.

However, what the story, even if true and rigorous, does not show is that economists can give an account of distributive justice. They can give a rational choice account of a distribution, and they can give a rational choice account of how a distribution determined by seizure and predation might be accepted by everyone and form the basis for a system of property rights and a market economy. But none of this answers any question about the moral legitimacy of holdings, whether at the beginning of time or at any particular moment in the continuing operation of the market.

The point should be obvious enough. The possessions ratified by a Humean convention, or the natural equilibrium in Buchanan's version of the story, may involve the most radical inequality. There is nothing particularly creditable about the procedures by which holdings are acquired; nothing particularly attractive about the personal features (strength, cunning, ruthlessness, and luck) on which the outcome is likely to be patterned; nothing, in short, that is likely to contribute to the legitimacy of holdings. Humean possession is not equivalent to a principle of First Occupancy (for a present holder may have violently dispossessed another just before the convention came into existence), and it is certainly not a Labor principle of acquisition along Lockean or Nozickian lines. ${ }^{58}$ Indeed, for all that we can say, some individuals may reach Buchanan's natural equilibrium or come to the Humean convention possessed of the bodies or persons of other individuals. Since there is nothing, on this account, morally to be said about the basis of these possessions, there is nothing to rule out slavery or cannibalism as features of the property system that is ratified in this way.

If Hume is right, no question of justice or legitimacy can be raised until there is agreement on some system of property rights along the lines we have been considering. This is because the very concept of justice is de-

58. J. Locke, The Second Treatise of Government $\$ \$ 22-25$ (P. Laslett rev. ed. 1963) (3d ed. 1698); R. Nozick, supra note 9, at 150-82. There is an important distinction between those libertarian theorists who follow Locke and Nozick and those who follow Hume and Buchanan in this regard. 
rived from the fact of this agreement. ${ }^{59}$ But nothing in his story shows that questions of justice cannot subsequently outstrip the terms of the original agreement or call them into question. For example, once the Humean convention is established, people will agree to abide by principles that, among other things, regulate the (post-convention) acquisition of new holdings. Hume suggests that a principle like First Occupancy will fill this role. ${ }^{60}$ But if people will come to judge post-convention acquisitions by this standard, they may be tempted in time to apply it also to what they know about the origin of pre-convention holdings. Even though they could not have had such a critical standard to apply to any acquisition unless pre-convention holdings had been recognized, still, once the process of deploying standards has gotten underway, there is nothing contradictory about turning those standards on the pre-convention holdings themselves and calling the whole basis of subsequent transactions into question. Particularly when we recall Coleman's emphasis on the ways in which the new institutions for protecting property may alter, over time, the balance of power among the property holders, there is nothing in the Humean story to insulate the pattern of existing holdings, either descriptively or normatively, from further challenge. Even if the enforcement institutions have been programmed to enforce only the regime of holdings recognized at the time they were set up, we know enough about how such institutions operate to recognize the possibility that they may be revised or reprogrammed if there is a sufficient shift in the balance of social power. The institutional entrenchment of a given set of property rights is as resilient and as fragile as the structure of power that sustains the institutions in question.

Thus, showing (as Hume does) that recognition of existing holdings is a precondition for the deployment of any principle of justice is not, in itself, a way of showing that the recognized holdings and the market outcomes that flow from them cannot be scrutinized by a principle of justice, and it is certainly not a way of showing that they are inalterable in the light of such scrutiny.

I found it surprising that Coleman did not make more of this point about justice in his critique of the rational choice story, particularly given

\footnotetext{
59. Hume writes:

After this convention, concerning abstinence from the possessions of others, is enter'd into, and every one has acquir'd a stability in his possessions, there immediately arise the ideas of justice and injustice; as also those of property, right, and obligation. The latter are altogether unintelligible without first understanding the former. Our property is nothing but those goods, whose constant possession is establish'd by the laws of society; that is by the laws of justice. . . . A man's property is some object related to him. This relation is not natural, but moral, and founded on justice. 'Tis very preposterous, therefore, to imagine, that we can have any idea of property, without fulling comprehending the nature of justice, and shewing its origin in the artifice and contrivance of men.
}

D. HUME, supra note 39 , at $490-91$.

60. Id. at 505-13. 
the role that distributive justice plays elsewhere in his work. ${ }^{61} \mathrm{He}$ does suggest at one point that the convention establishing property rules is likely to be unstable if it is not perceived as fair: "[T]hose who are relatively disadvantaged by the agreement will seek to destabilize it . . ."62 But it is not clear whether this sense of relative disadvantage refers to the distribution of holdings or merely to the distribution of the surplus secured by the agreement itself. ${ }^{63}$ In another essay later in the book, Coleman notes that a process of the sort discussed here "may freeze, or at least entrench, what is in fact a very unjust distribution of preconstitutional holdings." ${ }^{\circ 4}$ But again he obscures the point by continuing:

The initial assignment of rights is itself the outcome of rational bargaining. It will not follow, however, . . . that the allocation of property rights, and of the gains from trade made possible by them, is morally unassailable. That is because the allocation is the outcome of rational bargaining, and the rational distribution of resources that results from a bargain need not be a moral one. ${ }^{65}$

$\mathrm{He}$ adds in a footnote that "[t]his is just the question of whether rational bargaining also provides a theory of 'moral bargaining.' "'B6 But it is not just that: Even if the bargained distribution of the surplus is as moral as can be, the assignment of rights that results is still mainly determined by the respective holdings that the parties brought to the bargaining table. And there is nothing at all moral about that.

I have belabored this point and this discussion, not because I believe Coleman disagrees, but because there is always a temptation to think that a rational choice theory, with its emphasis on agreement, unanimity, and Pareto-improvement, and on the values of freedom and efficiency, necessarily legitimizes whatever it explains. Nobody is forced into a Humean convention, and everyone who is a party to it benefits, so who can complain? The fallacy is simple: To improve the plight of those who suffer in an unjust situation (or simply to gain their consent to such an improvement) is not to make the resulting situation a just one or even necessarily to mitigate the injustice. Everyone will agree to an improvement, and nobody will complain about the improvement (considered in itself). But everyone can agree without undermining his insistence that both the pre-

61. One example is in his application of the principle of corrective justice to tort. See supra text accompanying notes 19-28. There is no argument based on justice for protecting a Humean allocation from disruption or for repairing wrongful losses that people might suffer in the holdings that such an allocation provides them.

62. P. 274.

63. Of course, the latter may be partly determined by the former. Threat advantage in bargaining will be determined by the size of one's holding as well as by one's personal capacity to protect it.

64. P. 287 (footnote omitted).

65. P. 287 (footnote omitted).

66. P. 390 n.14. 
improvement distribution and the post-improvement distribution are unfair.

\section{ConCLUSION}

Like all collections of essays, this volume has its unsatisfactory aspects. The essays do not hang together perfectly, ${ }^{67}$ and there are both omissions and repetitions. There are some extensive comments in the endnotes (inserted, one presumes, at the editing phase) that.could well have been incorporated into the text. And the volume is marred by misprints and by the lack of an index.

All the same, this is a rich and stimulating volume which repays close attention. It provides the basis of a rigorous critique of EAL and of the general claims made for economic method in law and political theory. It demonstrates the author's considerable command of legal, technical, and philosophical skills. Above all, it whets the reader's appetite for more sustained presentations of Coleman's views on these topics. In the Preface he promises us a book called Accidents, ${ }^{68}$ and in the endnotes another entitled The Market Paradigm. ${ }^{69}$ Both will be well worth waiting for.

67. The essay on Dworkin's critique of positivism, for example, is quite different in its theme from all the others.

68. P. xii (footnote omitted).

69. P. 387 n.1. 
